\title{
Firms, Incomplete Contracts and Organizational Learning
}

\author{
Foss, Nicolai J.
}

Document Version

Final published version

Publication date:

1996

\section{License}

CC BY-NC-ND

Citation for published version (APA):

Foss, N. J. (1996). Firms, Incomplete Contracts and Organizational Learning. DRUID - Danish Research Unit for Industrial Dynamics. DRUID Working Paper No. 96-02

Link to publication in CBS Research Portal

\section{General rights}

Copyright and moral rights for the publications made accessible in the public portal are retained by the authors and/or other copyright owners and it is a condition of accessing publications that users recognise and abide by the legal requirements associated with these rights.

Take down policy

If you believe that this document breaches copyright please contact us (research.lib@cbs.dk) providing details, and we will remove access to the work immediately and investigate your claim. 


\section{$\mathbf{D}_{\text {ANSH }} \mathbf{R}_{\text {ESearch }} \mathbf{U}_{\text {NIt FoR }} \mathbf{I}_{\text {NDUStriaL }} \mathbf{D}_{\text {YNamics }}$}

DRUID WORKING PAPER NO. 96-2

Firms, Incomplete Contracts and

Organizational Learning

by

Nicolai J. Foss

April 1996 


\title{
Firms, Incomplete Contracts, and Organizational Learning
}

\author{
by \\ Nicolai J. Foss \\ Institute of Industrial Economics and Strategy \\ Copenhagen Business School \\ Nansensgade 19,6 \\ 1366 Copenhagen $\mathrm{K}$ \\ Denmark \\ Phone +4538152547 \\ Fax +4538152540 \\ E-MailESNJF@cbs.dk
}

\begin{abstract}
This explorative paper argues that the central problem of economic organization is adaptation to unforeseen contingencies. However, flexibility is a rather neglected issue in the theory of economic organization. This contrasts with much organization theory, in which the seeking and processing of information about the organization's key uncertainties is seen as a determinant of organizational form. The notion of incomplete contracts is argued to provide a means to bridging ideas from organizational economics and organization theory, particularly organizational learning. Incomplete contracts are not only important because they provide room for incentive problems, but more importantly because they allow firms to exploit processes of organizational learning that must always involve some unforeseen contingencies. Firms are seen as efficient institutional responses to learning processes that involve strongly complementary problem-solving activities.
\end{abstract}

\section{Keywords:}

The theory of economic organization, incomplete firm contracts, organizational learning, the existence of the firm.

JEL Classification:

D23, L14, D83 


\section{Introduction}

This paper links up with the literature on economic organization, but -- in contrast to this literature -- is founded on knowledge-based premises. Rather than conceptualizing the firm as an entity that is primarily kept together by transaction cost minimization, it seeks to extend the view of the firm as an entity whose primary role is to acquire, combine, utilize and upgrade knowledge [29, 9, 52, 25, 6]. More specifically, I seek to elaborate and extend from an economic perspective the idea that various types of economic organization primarily derive their raison d'etre from their ability to adapt to partly unanticipated changes in knowledge, much of which may be generated by the firm itself. Thus, the existence of the firm is rationalized in terms of its function as a repository of knowledge and seedbed of learning, rather than in terms of aligning incentives (as in $[53,39,21]$. This overall perspective is clearly related to the point in much organization theory that the organizational dynamic that is most determinative of organizational forms is the seeking and processing of information about the organization's key uncertainties ([52] is a particularly vivid, recent statement of this position).

A basic conceptualization of the firm as an adaptive and cognitive mechanism can be found in the seminal early contributions to the theory of economic organization $[24,4$, 19, 32]. Moreover, as already suggested, it will certainly not come as a surprise to modern contributors to organization theory (e.g., [52, 33, 34]) or evolutionary economics (e.g., [12, 54]) that the firm may be conceptualized in this way. But it is only present in modern mainstream economics in the distorted form of the argument that economic organization reflects efficient adaptation to the possibility of partly unanticipated strategic behavior, such as 'opportunism' [53, 26, 27,17].

One convenient way of conceptualizing the idea that various types of economic organization -- firms, hybrids and markets, to use Oliver Williamson's [53] typology -- are primarily instruments of adaptation to the partly unexpected is to that they are optionproviding institutions -- or, if you like, they embody reserves [29, 30]. Clearly, markets provide options in a rather general sense: They feature a menu of input and service options, and therefore allow us to postpone decisions. Hybrid forms, such as network governance, joint ventures, and much else, may be understood in option terms, too -- indeed, this has 
been a strong argument in favor of strategies of outsourcing on the part of firms placed in turbulent industries. Companies competing in such environments, such as, Nike, Inc. or Benetton, have based much of their competitive success on developing and maintaining flexible supplier relations. This has allowed Nike to generate and maintain a broad portfolio of options, and -- importantly -- to realize these options at the right time [44]. Thus, an options or flexibility perspective is directly relevant to strategic management (see [49]; that it is also relevant to the theory of economic organization is the overall message of this paper.

The options perspective is clearly applicable to markets and hybrids, because flexibility is very much part of the rationale of these institutions (cf. Hayek, 1945). But the perspective may be extended to firms. As Brian Loasby [30] has recently -- almost aphoristically -- put it, firms provide contracts for future options, whereas markets provide options for future contracts. It is this overall perspective on firms as providing contracts for future options which I suggest to elaborate in the ensuing pages. In fact, I shall go somewhat further than Loasby and argue that we may derive a rationale for firm organization from the options/flexibility perspective. In this perspective, firms exist because they can more efficiently coordinate collective learning processes than market organization is able to.

My specific design in this paper is the following. The starting point is a general discussion of adaptation. Adapting to unforeseen contingencies is the perhaps central problem of economic organization, and the theory of the firm needs to recognize this more fully. Recent work on the theory of the firm has argued that incompleteness of contracts -that not all future contingencies are covered by the contract -- is a necessary feature in a sound economic approach to organization [53, 17]. Basically, this is because incompleteness means that there is room for what is seen in recent work as the crucial determinant of economic organization, namely problems of aligning incentives.

However, incomplete contracts are not only important because they provide room for incentive problems, but perhaps more importantly because a structure of incomplete contracts is a structure around problem-solving and the learning that flows from the successful or successful approach to problems. Here, an open-ended structure is needed, because problem-solving and learning are activities that by their nature must involve 
contingencies that cannot be fully foreseen (although they can be partially imagined). I end by arguing that when processes of learning are strongly complementary -- in the sense that individual learning processes feed on each other -- these are best organized within a structure of incomplete contracts supported by centralized control, that is, within a firm. I take complementarity of individual learning processes to be a defining characteristic of organizational learning; thus, the organization does not learn if only one member learns (admittedly, this is somewhat narrow, see [22] for a broader view).

\section{Adaptation}

As a matter of rational, and perhaps also historical, reconstruction, there are two overall conceptualizations of the economic problem to be found in the history of economic doctrines. The first, and dominant, was perhaps best stated by Stanley Jevons:

'The problem of economics may, as it seems to me, be stated thus: Given, a certain population, with various needs and powers of production, in possession of certain lands and sources of material: required, the mode of employing their labor which will maximize the utility of the produce' [23, p. 267].

Thus, in this conceptualization, the economic problem is seen essentially as a static optimization problem, and there is an implicit presumption that if all data are given to a single mind, this mind can work out the optimal allocation/distribution patterns [19].

Now there are several ways in which this caricature may be relaxed, and, in fact, is relaxed. One such way is to take the starting point in what is arguably still the paradigmatic economic model, namely the Arrow-Debreu model [8], and introduce transaction costs into it. This means that at least some forward markets will be closed; everything cannot be settled at the initial point of time and there will be a need for later decisions to be made as time and states of nature unfold [45]. In a restricted sense, there is a need for flexibility.

How radical this solution is arguably depends on how we interpret the notion of transaction costs. In one interpretation -- one that is easy to handle in formal models -- 
transaction costs are simply a fraction of the resource that is lost for whatever reason in a transaction. Thus, transaction costs are not really different from production costs; they are merely incurred after the product has materialized rather than before. But in another and more interesting interpretation, transaction costs are knowledge costs -- in mainstream theory, the various costs of being asymmetrically and imperfectly informed. However, as normally used in mainstream theory, asymmetric and imperfect information and the transaction costs they imply are properties of a decision problem that is designed by the theorist as confronting some actor on an ex ante basis. The design of some institution, organization or contract is the ex post outcome. For example, the employer (principal) initially faces the problem of not precisely knowing the capabilities of the agent he plans to hire; he knows that he cannot constantly monitor the agent's actions, that there is a stochastic variable that impinges on the output of the agent, etc. His choice problem is to design some incentive scheme that minimizes the guaranteed wage, while still having the agent sign the contract and supply a high effort-level.

This basic principal-agent setting has been employed -- with suitable modifications -- as an economic approach to organization in countless contributions (for overviews, see [39]). Critics of the economic turn in organization theory (such as [10]) has argued that it is excessively methodologically individualist, that it operates with an overly cynical and unrealistic view of human nature, is too functionalist, etc. To these methodological critics may be added a more substantial critique: The overriding problem of handling the major uncertainties confronting the organization -- including adapting to unforeseen changes -- so often stressed in much organization theory is neglected in a large part of the economic approach to organizations.

The fundamental principal-agent model is not in essence different from Jevons' conceptualization of the economic problem: although the data of the problem are not known with certainty, there is an optimal solution to the contract design problem that can be worked out by the principal at time 0 -- and which continues to be optimal throughout contract execution. Thus, there will be no need for adaptation.

Now adaptation is really the main issue in the second major conceptualization of the economic problem to found in the history of economic doctrines. It is perhaps best 
associated with the work of Friedrich von Hayek and his fellow Austrians, but present-day evolutionary and post-Marshallian economists [46, 47, 29, 30] also belong to this intellectual current. The starting premise of this tradition is the Hayekian point that economic problems are consequences of unexpected change, because it is this kind of change that necessitates revisions in plans [19].

It is hard to underestimate the difference between the two traditions (for an attempt at estimation, see [31]), not the least with respect to how institutions and organizations are conceptualized. In the latter -- evolutionary-Austro-Marshallian -- tradition, markets, firms, and entrepreneurs, are not primarily seen as efficient mechanisms for the allocation of given resources -- rather, they are seen as agents of a society-wide discovery, or learning, process.

Thus, markets are not primarily efficient incentive mechanisms; instead, they are embodiments of options, and it is this role that makes markets such effective devices for adapting to unforeseen changes. Now options within a market setting are primarily provided by firms; for example, a firm may vertically disintegrate and instead utilize the options of 'the market', that is, of potential supplier firms. This may be a rational response to, for example, unforeseen changes in the consumer preferences that characterize the firm's own market, as is the case with Nike confronting a strongly volatile market for athletic shoes [44].

But the firm may also itself generate contingencies that are not only unforeseen relative to other firms, but also -- at least to some extent -- to itself. Firms will do this to the extent that they engage in learning. For example, as any innovation theorist will know, R\&D efforts constantly generate surprises, some of which turn out to be serendipitous. Thus, flexibility is needed, not only in the market context, but also within the firm itself. In the following sections, I suggest to expand the options/flexibility perspective from markets to firms. The attempt to do this begins with a discussion of contractual incompleteness.

\section{Incomplete Contracts}

Since Coase [4], contractual incompleteness -- that is, the circumstance that certain contingencies are not provided for in the contract -- has been an essential, if somewhat 
problematical, feature of the theory of the firm. As Coase argued, incompleteness is not only characteristic of employment contracts but also of, for example, long supplier contracts.

In addition to its obvious empirical importance, recent research has demonstrated that incompleteness of contracts is a necessary condition for telling a convincing story about the boundaries of firms. This is so because 'comprehensive' (i.e., not-incomplete) contracts do not allow the analyst to say much about ownership; for example, in a principal-agent setting, a contract between an independent supplier, and a contract between the manager of one of the firm's divisions may be completely alike. This implies that in order to tell a sensible story about the boundaries of the firm -- in recent research interpreted to refer to what the firm owns and what it doesn't own -- it is necessary to introduce incompleteness of contracts. In fact, ownership is interpreted to mean the right to control assets under circumstances that are not contractually stipulated (for the details of the argument, see [17]).

Now to the extent that contractual incompleteness is rationalized -- rather than simply asserted -- this is done by pointing to bounded rationality, to information costs, or to some mixture of the two. Thus, it is impossible for cognitive reasons or too costly to specify the full decision tree. For example, the approach of Oliver Hart and John Moore $[18$, p. 756$]$ is to '...focus on the cost of writing a contingent clause in a sufficiently and unambiguous way that it can be enforced'. But often, there is a presumption that in principle the relevant information could be included in the contract, if only the parties would bear the costs of information collection and processing; the information is there, as it were. As an exemplification, here is how incompleteness of contracts is described in a recent contribution:

'Many contracts specifying state-contingent outcomes that economic agents write to regulate their transactions are incomplete. They neglect information about the state of the world that is in principle available to the parties to the contract and would be optimal for them to include' [2, p. $1085]$.

One of the pioneers in the modern development of incomplete contracts, Oliver Hart, has recently argued that bounded rationality is not really necessary for the modern theory of the firm. What is necessary is rather that -- although the parties to a contract may 
in fact conceive of all the relevant contingencies -- they are not able to '...write them down in a clear enough way that an outside arbiter, such as a court, can verify them' [16, p.698].

One could argue, of course, that this shifts the boundedness of rationality from the parties to the transaction to the courts. But that is not really the gist of the argument; rather, it amounts to reducing bounded rationality and the category of the unexpected to a form of asymmetric information. For whatever reason, the parties to the contract know something that cannot be known by the courts.

Another important formal contributor to the modern theory of economic organization, David Kreps [26, 27], has adopted a different position. He seems to accept bounded rationality, if in a rather hesitant way. In an explorative paper on how corporate culture may be interpreted in the context of organizational economics, Kreps explicitly grapples over several pages with the notion of unforeseen contingencies. In his theory, corporate culture is essentially a reputation capital that tells employees of the firm and external suppliers how the firm will react to unforeseen contingencies.

An important point that Kreps hints at, but does not really explore, is that there are degrees of 'unexpectedness' -- degrees of surprise, as George Shackle [50] called it --, from the completely unexpected to that which can be anticipated in rough outline, if not in details. The important point is that it is possible to provide for the latter kind of unexpectedness:

'Introspection suggests that while a particular contingency may be unforeseen, provision for it is not completely impossible. While the exact circumstances of future contingencies may be unimaginable (or too costly to think through), aspects of those contingencies follow patterns' [26, p.117].

Kreps goes on to argue that it is possible to formally model behavior designed to meet partially unexpected contingencies, and a formal later paper [27] in fact undertakes such modelling. But it is perhaps not the exact choice theoretic dimension of Kreps' discussion that is the most appealing aspect -- at least in the context of the present paper --, but rather his suggestion that various 'remedies that may or may not be applicable to a wide range of circumstances' [26, p. 117] exist precisely because of their role in meeting unforeseen 
contingencies. His examples are cash and fire extinguishers -- but the perspective may be extended to firm.

In fact, Kreps [26, 27] himself does this, by arguing that governance structures are adopted by agents that are sufficiently rational to expect the unanticipated, as it were. This is quite credible, since it simply seems to be a commonplace observation that agents choose governance structures -- for example, types of relational contracting -- that really do provide mechanisms for adaptation to partially unanticipated contingencies. But it is quite another thing, and much less credible, to say that agents are so rational that they can choose on an ex ante basis the transaction cost minimizing governance structure. In fact, this runs directly counter to the idea of bounded rationality (cf. [11]).

\section{Contracts and Learning}

In the mainstream theory of economic organization, contractual incompleteness is seen as important because it -- in conjunction with opportunistic/morally hazardous behavior and relation-specific investments -- helps determine patterns of ownership, for example, of the firm's physical assets [17]. And in a sense, there is a 'negative' dimension to incompleteness, because incompleteness provides leeway for opportunism. This is also true for contributions such as Kreps [26] that explicitly tries to make a bridge to more organizational and behaviorally oriented studies.

But there is another -- perhaps more 'positive' -- way of conceptualizing incomplete contracts, namely as structures around problem-solving. As Coase noted in connection with a discussion of long-term contracts,

'...owing to the difficulty of forecasting, the longer the period for the contract is for the supply of the commodity or service, the less possible, and indeed, the less desirable it is for the person purchasing to specify what the other contracting party is expected to do. It may well be a matter of indifference to the person supplying the service or commodity which of several courses of action is taken, but not to the purchaser of that service or commodity. But the purchaser will not know which of 
these several courses he will want thepplier to take. Therefore, the service which is being provided is expressed in general terms, the exact details being left until a later date' [4, p. 84].

Coase here begins to talk about a long-term, incomplete contract between a firm and its supplier -- that is, between two independent firms -- but then slips directly into associating the firm with hierarchical direction: 'When the direction of resources...becomes dependent on the supplier in this way, that relationship which I term "the firm" may be obtained' [4, p. 84]. He admits [4, p. 96n10] that there may be more or less direction, and that it is, accordingly, hard to draw a hard and fast line between the firm and the market.

However, Coase's own discussion suggests that the firm-hierarchy choice somehow turns on the character of the problem solving that is involved in the relation. In particular, if the relevant problem-solving relate to activities that are closely complementary -- strongly inter-connected -- achieving efficient coordination may require common ownership [46, p.83, 32, 36] (I return to this later).

Problem-solving is an activity with distinctly hierarchical and complementary features. Thus, one solves problems by dividing problems into sub-problems, solving these sub-problems, checking whether the solved sub-problems imply a solution to the overall problem, performing further solution of the sub-problems if they do not fit into an overall solution, etc. In other words, problem-solving begins with the generic features, then moves down the hierarchy in terms of detail. This process of decomposing problems and solving sub-problems is clearly a conjectural -- trial and error -- process [29, 30]; for example, one cannot ex ante be certain that one has performed the right decomposition. Moreover, one does not know ex ante that the solved sub-problems fit into a larger-scale solution -- that the right relation of complementarity has been achieved; that, too, is a conjecture.

As any modern organizational theorist knows, hierarchical coordination -- at least in an evolving environment and in firms of more than negligible complexity -- is very much characterized by these features. It is therefore essentially a learning process, rather than a matter of simply and mechanistically issuing the right commands and underscoring these by the right incentives and the right doses of monitoring (as in organizational economics, see 
[39]). This may be illustrated by referring to important recent work by Luigi Marengo [34].

Taking his cues from Cyert and March [7], Marengo is particularly interested in the coordination of individual learning processes inside the firm, and how a stock of organizational knowledge emerges from the interaction of these learning processes. In his simulation model, agents do not have any prior knowledge of the environment they are facing and they do not possess a shared partition of the states of the world (that is, there is no common knowledge).

However, such a shared partition is necessary for coordination - for example, understanding the demand of the exogenous market and coordinating this with the different shops inside the firm - to take place. And, in fact, as demonstrated by Marengo's simulations, coordination emerges gradually and spontaneously, as agents interact under given organizational structures and under the impact of given environments. However, the precise character and content of the organizational knowledge stock is inherently unpredictable. It is, in effect, a partly unforeseen contingency.

This casts a quite different light over the incompleteness of contracts, one that does not focus on the potential for opportunistic or morally hazardous behavior created by incompleteness. Rather, a structure of incomplete contracts is necessary for coordination. Moreover, incompleteness may be of distinct value because it allows the firm to learn, to develop its competences, to create (and realize) options, to benefit from emergent -- and therefore partially unforeseen -- strategies. Thus, to the extent that an essential part of the nature of the firm is its role as a strategy-making entity, this role is best understood in the context of a framework of incomplete contracts.

The bottom-line really is that contractual incompleteness is an instrument of adaptation. Importantly, it allows the firm to adapt to and exploit partly unanticipated learning which the firm itself generates, such as serendipities in R\&D, emergent strategies, etc. That such an instrument is in fact necessary follows from a basic epistemological impossibility theorem: future learning and knowledge cannot be fully anticipated, for if it could, it would be present knowledge and not future knowledge [41] .

Thus, incomplete contracts allow for the generation inside firms of new options and the realization of the those options -- in short, it allows the working of a process of variety 
generation and selection that is internal to firms [51]. Since individual learning processes, and perhaps even more so, organizational learning processes, imply the emergence of unforeseen contingencies, incompleteness of contracts and (organizational) learning would seem to be closely intertwined concepts. The emergence of a stock of organizational knowledge requires a framework of incomplete contracts -- one that is supplied by firm organization. This in turn suggests that there may some intimate relation between organizational learning and the existence of the firm. I discuss this next.

\section{Knowledge, Direction, and Flexibility}

The prevailing theories of the existence of firms are almost all based on the claim that firm organization allows for better investments in relation-specific assets that markets do, and that firms exist for this reason $[53,17]$. These theories are incentive-based, rather than knowledge-based, in the sense that the alignment of incentives is seen as the overriding issue of economic organization; it is essentially because incentives to invest in relation-specific assets are perverse under market organization that firms exist. As a more general matter, organizational forms reflect ways of damping or solving potential incentive problems. Moreover, notions of morally hazardous behavior -- such as opportunism -- are seen to be necessary in order to satisfactorily address the existence of firms. Considerations of knowledge accumulation and utilization appear at most implicitly.

However, Harold Demsetz [9] argued that morally hazardous behavior is not really necessary for understanding the existence of the firm. Instead, he suggested that there is an intimate link between knowledge and hierarchical direction, a link that, therefore, accounts for the existence of firms. As Demsetz explained:

'Firms and industries must form a pattern of economic organization that takes account of the need for acquiring knowledge in a more specialized fashion than the manner in which it will be used. Those who are to produce on the basis of this knowledge, but are not possessed of it themselves, must have their activities directed by those who possess (more of) the knowledge. Direction substitutes for education (that is, for the transfer of the knowledge itself)' [9, p. 159]. 
According to Demsetz, it is therefore specialization in terms of knowledge that provides the ultimate reason for the existence of hierarchical direction and (therefore) the firm.

A further stride forward in the construction of a knowledge-based theory of the firm has recently been taken by Kathleen Conner and C.K. Prahalad [6]. They argue that firms exist because they are often better able than markets to cultivate what they call a 'knowledge-substitution effect' and a 'flexibility effect'. As a general matter, knowledgesubstitution refers to how the knowledge endowments of different agents are applied in a productive venture (actually, 'knowledge-direction' would perhaps be a better word). As a starting point, each agent is presumed to have access to his own endowment of knowledge. However, the insights and knowledge of different agents may be made available to other agents, for example, through apprenticeship, through suggestions in communication, and through hierarchical direction. Knowledge-substitution takes place when the knowledge of a superior is used for directing the actions of a sub-ordinate, that is, when the latter is told to perform some activity. As indicated by the above quotation from Demsetz, hierarchical direction epitomizes knowledge-substitution.

Assuredly, knowledge-substitution may take place in a market setting (as when I instruct a gardener as to how my garden should be fixed). However, to the extent that the hierarchy reduces, for example, bargaining costs, knowledge-substitution may perform more efficiently within the firm than in the market $[6,37]$. The typical arguments advanced in favor of this view, is that firm organization -- because of the continuity of association between inputs -- is an efficient vehicle for cultivating and offering a shared frame of reference -- a stock of organizational knowledge -- whereas market organization cannot develop and offer a cognitive frame of reference that is equally fine-grained.

The flexibility effect refers to the superior flexibility that hierarchy may obtain relative to market contracting in influencing input-owners' actions in response to partly unexpected new developments and new learning $[4,28,6]$. This goes directly to the heart of what has been said up til now about organizational learning and incomplete contracts.

As has also already been observed, what Conner and Prahalad call the flexibility effect is a feature of firms that has been strangely missing from most of the contractual 
literature on firm organization. It is strange, considering that the issue was placed right at the center of the theory of the firm by Ronald Coase, as witnessed by the above quotation from Coase [4] (Section 4).

The firm may obtain superior flexibility, because the hierarchy may economize on bargaining costs relative to market organization in the case of meeting and handling major unforeseen contingencies. Moreover, flexibility is facilitated because firm organization supplies a stock of organizational knowledge that reduces various information and coordination costs because it eases the interpretation, communication, and handling of unforeseen contingencies.

Crucially, the flexibility function affects the dynamics of knowledge-acquisition and organizational learning -- it allows rapid response to new developments and new learning, because it does not require renegotiation of contracts (as market contracting possibly would). In the following, I utilize these ideas for deriving a knowledge-based rationale for the firm that is in conformity with the options/flexibility theme that has been the overall theme of this paper.

\section{Strategy, Learning, and the Existence of Firms}

Recent strategy thinking has been much more open to the idea of viewing firms as embodying flexibility and the generation of new options through organizational learning than has contemporary economics. In an extremely influential article, C.K. Prahalad and Gary Hamel [43], highlighted what they called 'the core competence of the corporation', and defined it as '...the collective learning in the organization, especially how to coordinate diverse production skills and integrate multiple streams of technology' [43, p.84]. Core competence is important because it feeds the firm's options generating capability, that is, creates the possibilities to 'spawn new unanticipated products' (ibid.).

Building on Prahalad and Hamel's work, Costas Markides and Peter Williamson [35] constructed a detailed taxonomy of firm asset dynamics. Some of these asset dynamics refer to more static exploitation of given assets. This is the case, for example, of what they 
called 'asset amortization', that is, the potential to reap economies of scope across strategic business units that can share the same asset, and also, to a smaller extent, of what they called 'asset improvement', that is, the potential to use a competence accumulated in the course of building/maintaining a strategic asset in one business unit to help improve an existing strategic asset in another strategic business unit. But they also introduced the concepts of 'asset creation', that is, the potential to utilize a competence developed through the experience of building strategic assets in existing businesses, to create a new asset in a new business, and 'asset fission', that is, the potential for the process of related diversification to expand an organization's existing pool of competences because, as it builds strategic assets in a new business, it will learn new skills that in turn will allow to improve the existing assets in existing businesses.

Now these asset dynamics involve -- as described by Markides and Williamson -processes of organizational learning, some more exploitative, some more explorative (to use March's [33] terms). The bottomline is that they all involve a collective and synergistic dimension to the relevant learning. A more traditionally economic way of phrasing this is to say that there are (Edgeworth) complementarities between the relevant activities, such as relevant strategic business units $[32,36]$. Formally, complementarity between, say, two activities obtains when doing more of one of the activities increases the yield from doing more of the other activities, and vice versa.

For example, when Samsung Electronics Co. in these years strongly expands its number of strategic business units and alliances within the broad area of electronics, this is because they conjecture that there may be many complementarities between the relevant activities, and that this will foster the collective learning of the organization, increase the number of options Samsung is able to create (e.g., new product options), and hence upgrade the stock of collective knowledge of the corporation [40]. For example, accumulating knowledge within some aspect of computer technology may feed on the accumulation of knowledge within some are of telecom and vice versa, particularly when these two overall streams of technology are converging. There may for Samsung exist a complementarity in the specific sense that the marginal return of accumulating knowledge within computer technology is increasing in the level of the stock of knowledge about telecom, and vice 
versa. Thus, there may be a self-propelling aspect of the process of providing options through organizational learning.

Because firms come equipped with incomplete contracts, and a supporting infrastructure of corporate cultures [26] and management heuristics [42], they may under certain circumstances be the proper framework around the process of providing new options and realizing these; with Loasby [30], they may indeed 'provide contracts for future options'. They may not always be the proper framework -- for path-dependencies, organizational rigidities of all kinds, framing effects, and much else may stifle the process of creating and realizing options [48]. Moreover, for some types of learning -- for example, learning within a modular system -- markets may actually be superior to firms (see the analysis in [28]).

In terms of the previous discussion, what may allow firms to provide and realize new options -- to carry out new strategies based on previous organizational learning -- is precisely the operation of the flexibility and the knowledge substitution effects. Clearly, creating new options through processes of organizational learning involving various complementarities must involve creating unforeseen contingencies; as a result this process requires contractual incompleteness. But in order to turn organizational learning and the options this may create into commercially viable products, leadership and management is required; flexibility must be exploited to be attractive and this is done, at least partly, by hierarchical direction -- that is, by knowledge-substitution.

We may found a rationale for the firm in these ideas, that is to say, by combining our overall view of the firm as an entity that provides new options through a process of organizational learning that is underpinned by a structure of incomplete contracts. One important component of such a rationale lies in relations of complementarity between intrafirm assets and activities.

Organizational economists Paul Milgrom and John Roberts [36, 38] have treated such relations of complementarity in production in much detail. They refer to the coordination problems that may arise between complementary activities as 'coordination problems with design attributes' (design problems', for short). More specifically, these are problems with two important features. First, there is some knowledge of the form of the optimal solution, that is, how relevant variables should be related (for example, the effort 
levels of workers in a team). Second, failing to achieve the right relation between the variables is more costly than other errors, including minor misspecifications of the overall pattern, as long as the individual activities fit [38, p. 91]. Mundane examples may be the sport of crew, the performance of a ballet company or a symphony orchestra. These are examples of synchronization problems; assignment problems may other examples. Firms often solve design problems by routinization which makes possible a certain amount of decentralized decision-making.

But decentralization often performs poorly to the extent that the optimal resource allocation significantly depends on the use of knowledge that is not given to personnel at the operating level [38, p.92]. Organizational restructuring, new product launches, the stimulation of inter-divisional knowledge flows, etc. are examples of design problems with an innovation attribute. These problems -- which normally will involve the emergence of some unforeseen contingencies -- favor intensive knowledge flows and some extent of centralized control. Thus, to the extent that the firm may be seen as providing contracts for new options, this is accompanied by some measure of centralized control.

The severity of design problem hinges on the degree of complementarity that is involved. As Harald Malmgren [32] suggested, the existence of the firm is explainable as an efficient response to severe design problems:

'I wish to suggest...that where output and profitability of various production units are closely interdependent, the firm is formed to undertake decisions concerning all or some of the production units simultaneously, so as to maximize the joint profit and total output' [32, p.412].

In terms of the present discussion, we may use this idea to argue that when the provision and exploitation of options involve activities that are strongly complementary, the firm is formed. In other words, the firm is needed when there is strong interdependence between the various learning processes that result in new options. The coordination of such learning processes requires a framework of incomplete contracts, because there is a need for being able to react to and adapt to unforeseen contingencies that arise during the process of learning (i.e., the flexibility effect). Specifically, some measure of centralized control -- 
some knowledge-substitution -- is needed for such design problems with innovation attributes. Thus, hierarchical direction within a framework of incomplete contracts -- that is, a firm -- is needed.

Conversely, providing and exploiting options that do not involve strongly complementary processes of learning -- for example, inventing and producing a new component within a standardized hi-fi system -- can be left to markets [28]. Essentially, this is because there are no real design problems; these have already been solved by the provision of a standard.

\section{Concluding Comments}

The firm, organizational economist say, is a nexus of contracts. This way of putting things is important both for what it says and for what it says only implicitly. It is important, of course, because it directs our attention towards the property rights and incentive schemes of firms; but it is also important because of its omissions, its lack of attention to some important implications of the involved contracts.

It has been argued that the incompleteness of contracts is not only important to the theory of economic organization because it provides the necessary leeway for postcontractual strategic behavior in the form 'opportunism' under the impact of partly unforeseen contingencies. Incompleteness of contracts is also important because incomplete contracts provide room for partially unexpected and potentially beneficial organizational learning and because it allows the process of hierarchical direction to take place.

Thus, rather than being a problem (because it opens the door to incentive problems), the incompleteness of contracts is a distinct virtue because it provides room for knowledge accumulation and for experimentation. It is precisely the incompleteness of contracts that allows the firm to function as an adaptive, cognitive system. 


\section{References}

[1] Alt, James E. \& Kenneth E. Shepsle, Eds., Perspectives on Positive Political Economy. (Cambridge University Press, Cambridge, 1990).

[2] Anderlini, Luca \& Leonardo Felli, Incomplete Written Contracts: Undescribable States of Nature, Quarterly Journal of Economics, 109 (1994) 1085-1124.

[3] Christensen, Jens F. \& Nicolai J. Foss, Dynamic Corporate Coherence and CompetenceBased Competition, paper presented at The Third International Workshop on CompetenceBased Competition, Ghent, November 16-18, 1995.

[4] Coase, Ronald H. The Nature of the Firm, Economica, 4 (new series) (1937), 386-405, in: Jay B. Barney \& William G. Ouchi, Eds., Organizational Economics (Jossey-Bass Publishers, San Francisco, 1986).

[5] Cohen, Michael D., Individual Learning and Organizational Routine: Emerging Connections, Organization Science, 1 (1991) 135-139.

[6] Conner, Kathleen R. \& C.K. Prahalad, 'A Resource-Based Theory of the Firm: Knowledge vs. Opportunism, Organization Science (forthcoming in 1996).

[7] Cyert, Richard \& James G. March, A Behavioral Theory of the Firm, (Englewood Cliffs, Prentice-Hall, 1963)

[8] Debreu, Gerard, Theory of Value (Wiley, New York, 1959).

[9] Demsetz, Harold, The Theory of the Firm Revisited, in: idem., Ownership, Control and the Firm: The Organization of Economic Activity (Basil Blackwell, Oxford, 1990).

[10] Donaldson, Lex, The Ethereal Hand: Organizational Economics and Management Theory, Academy of Management Review, 15 (1990) 369-381.

[11] Dow, Greg, The Function of Authority in Transaction Cost Economics, Journal of Economic Behavior and Organization, 8 (1987) 13-38.

[12] Foss, Nicolai J., Theories of the Firm: Competence and Contractual Approaches, Journal of Evolutionary Economics, 3 (1993) 127-144.

[13] Foss, Nicolai J., The Two Coasian Traditions, Review of Political Economy, 6 (1994), 35-61.

[14] Foss, Nicolai J., Knowledge-Based Approaches to the Theory of the Firm: Some 
Critical Comments, Organization Science (forthcoming, 1996a).

[15] Foss, Nicolai J., More Critical Comments on Knowledge-Based Theories of the Firm, Organization Science (forthcoming, 1996b).

[16] Hart, Oliver D., Is "Bounded Rationality" an Important Element of a Theory of Institutions?, Journal of Institutional and Theoretical Economics, 146 (1990) 696-702.

[17] Hart, Oliver D., Firms, Contracts, and Financial Structure (Clarendon Press, Oxford, 1995).

[18] Hart, Oliver D. \& John Moore, 'Incomplete Contracts and Renegotiation', Econometrica, 45 (1988) 755-785.

[19] Hayek, Friedrich A. von (1945), The Use of Knowledge in Society, in: idem., Individualism and Economic Order (Chicago University Press, Chicago, 1948).

[20] Henderson, Rebecca, The Evolution of Integrative Capability: Innovation in Cardiovascular Drug Discovery, Industrial and Corporate Change, 3 (1994) 607-630.

[21] Holmström, Bengt \& Paul Milgrom, The Firm as an Incentive System, American Economic Review, 84 (1994) 972-991.

[22] Huber, George P., Organizational Learning: The Contributing Processes and The Literatures,' Organization Science, 2 (1991) 88-115.

[23] Jevons, William Stanley, The Theory of Political Economy (4th ed.) (Macmillan, London, 1911).

[24] Knight, Frank H., Risk, Uncertainty, and Profit (originally publ. in 1921) (Augustus M. Kelley, New York, 1965).

[25] Kogut, Bruce \& Udo Zander, Knowledge of the Firm, Combinative Capabilities, and the Replication of Technology, Organization Science, 3 (1992) 383-397.

[26] Kreps, David. M., Corporate Culture and Economic Theory, in: James E. Alt \& Kenneth E. Shepsle, Eds., Perspectives on Positive Political Economy. (Cambridge University Press, Cambridge, 1990).

[27] Kreps, David M., Static Choice in the Presence of Unforeseen Contingencies, in Partha Dasgupta, David Gale, Oliver D. Hart \& Eric Maskin, Eds., Economic Analysis of Markets and Games: Essays in Honour of Frank Hahn (MIT Press, Cambridge, 1992).

[28] Langlois, Richard N. \& Paul Robertson, Firms, Markets and Economic Change (Routledge, London, 1995). 
[29] Loasby, Brian, Choice, Complexity, and Ignorance (Cambridge University Press, Cambridge, 1976).

[30] Loasby, Brian, Understanding Markets (Mimeo University of Stirling, Stirling, 1994).

[31] Machovec, Frank M. Perfect Competition and the Transformation of Economics (Routledge, London, 1995)

[32] Malmgren, Harold B., Information, Expectations, and the Theory of the Firm, Quarterly Journal of Economics, 75 (1961) 399-421.

[33] March, James G., Exploration and Exploitation in Organizational Learning, Organization Science, 2 (1991) 71-87.

[34] Marengo, Luigi, Structure, Competence, and Learning in an Adaptive Model of the Firm, (Papers edited by the European Study Group for Evolutionary Economics, \#9203, Freiburg, 1992).

[35] Markides, Constantinos C. \& Peter J. Williamson, Related Diversification, Core Competences and Corporate Performance, Strategic Management Journal, 15 (Special Issue) (1994), 19-166.

[36] Milgrom, Paul \& John Roberts, The Economics of Modern Manufacturing: Technology, Strategy and Organization, American Economic Review, 80 (1990a) 511-528.

[37] Milgrom, Paul \& John Roberts, 'Bargaining Costs, Influence Costs, and the Organization of Economic Activity,'(1990b), in: James E. Alt \& Kenneth E. Shepsle, Eds., Perspectives on Positive Political Economy. (Cambridge University Press, Cambridge, 1990).

[38] Milgrom, Paul \& John Roberts, Economics, Organization, and Management (PrenticeHall, Boston, 1992).

[39] Miller, Gary J., Managerial Dilemmas: The Political Economy of Hierarchy, (Cambridge University Press, Cambridge, 1992).

[40] Nakarmi, Laxmi, Kevin Kelly \& Larry Armstrong, Look Out, World - Samsung is Coming, Business Week, June 26, 1995.

[41] O'Driscoll, Gerald P. \& Mario Rizzo, The Economics of Time and Ignorance (Basil Blackwell, Oxford, 1985)

[42] Penrose, Edith T., The Theory of the Growth of the Firm (Oxford University Press, Oxford, 1959). 
[43] Prahalad, C.K. \& Gary Hamel, The Core Competence of the Corporation, Harvard Business Review, 68 (1990) 79-91.

[44] Quinn, James Brian, Intelligent Enterprise (Free Press, New York, 1992).

[45] Radner, Roy, Competitive Equilibrium Under Uncertainty, Econometrica, 36 (1968) 31-58.

[46] Richardson, George B., Information and Investment (Oxford University Press, Oxford, 1960/1990).

[47] Richardson, George B., The Organisation of Industry, Economic Journal, 82 (1972) 883-896.

[48] Rumelt, Richard P., Organizational Inertia and Transformation, in: Cynthia A. Montgomery, Ed., Evolutionary and Resource-Based Approaches to the Firm: Towards a Synthesis (Kluwer, Boston, 1995).

[49] Sanchez, Ron, Strategic Flexibility, Firm Organization, and Managerial Work in Dynamic Markets: A Strategic-Options Perspective, Advances in Strategic Management, 9 (1993) 251-291.

[50] Shackle, George L.S., Economics and Epistemics (Cambridge University Press, Cambridge, 1972).

[51] Simon, Herbert A., The Architecture of Complexity, Proceedings of the American Philosophical Society, 106 (1962) 467-482.

[52] Stinchcombe, Arthur L., Information and Organizations (University of California Press, Berkeley, 1990).

[53] Williamson, Oliver E., The Economic Institutions of Capitalism (The Free Press, New York, 1985).

[54] Witt, Ulrich, Imagination and Leadership: The Neglected Dimension of an (Evolutionary) Theory of the Firm, paper prepared for the Workshop 'Technology and the Theory of the Firm - Social and Economic Perspectives', Reading, UK, May 14-16, 1995. 


\section{$\mathbf{D}_{\text {anish }} \mathbf{R}_{\text {esearch }} \mathbf{U}_{\text {nit for }} \mathbf{I}_{\text {ndustrial }} \mathbf{D}_{\text {ynamics }}$}

The Research Programme

The DRUID-research programme is organised in 3 different research themes :

\section{- The firm as a learning organisation}

- Competence building and inter-firm dynamics

- The learning economy and the competitiveness of systems of innovation

In each of the three areas there is one strategic theoretical and one central empirical and policy oriented orientation.

\section{Theme A: The firm as a learning organisation}

The theoretical perspective confronts and combines the ressource-based view (Penrose, 1959) with recent approaches where the focus is on learning and the dynamic capabilities of the firm (Dosi, Teece and Winter, 1992). The aim of this theoretical work is to develop an analytical understanding of the firm as a learning organisation.

The empirical and policy issues relate to the nexus technology, productivity, organisational change and human ressources. More insight in the dynamic interplay between these factors at the level of the firm is crucial to understand international differences in performance at the macro level in terms of economic growth and employment.

\section{Theme B: Competence building and inter-firm dynamics}

The theoretical perspective relates to the dynamics of the inter-firm division of labour and the formation of network relationships between firms. An attempt will be made to develop evolutionary models with Schumpeterian innovations as the motor driving a Marshallian evolution of the division of labour.

The empirical and policy issues relate the formation of knowledge-intensive regional and sectoral networks of firms to competitiveness and structural change. Data on the structure of production will be combined with indicators of knowledge and learning. IOmatrixes which include flows of knowledge and new technologies will be developed and supplemented by data from case-studies and questionnaires. 


\section{Theme C: The learning economy and the competitiveness of systems of innovation.}

The third theme aims at a stronger conceptual and theoretical base for new concepts such as 'systems of innovation' and 'the learning economy' and to link these concepts to the ecological dimension. The focus is on the interaction between institutional and technical change in a specified geographical space. An attempt will be made to synthesise theories of economic development emphasising the role of science based-sectors with those emphasising learning-by-producing and the growing knowledge-intensity of all economic activities.

The main empirical and policy issues are related to changes in the local dimensions of innovation and learning. What remains of the relative autonomy of national systems of innovation? Is there a tendency towards convergence or divergence in the specialisation in trade, production, innovation and in the knowledge base itself when we compare regions and nations?

\section{The Ph.D.-programme}

There are at present more than 10 Ph.D.-students working in close connection to the DRUID research programme. DRUID organises regularly specific $\mathrm{Ph}$.D-activities such as workshops, seminars and courses, often in a co-operation with other Danish or international institutes. Also important is the role of DRUID as an environment which stimulates the Ph.D.-students to become creative and effective. This involves several elements:

- access to the international network in the form of visiting fellows and visits at the sister institutions

- participation in research projects

- access to supervision of theses

- access to databases

Each year DRUID welcomes a limited number of foreign Ph.D.-students who wants to work on subjects and project close to the core of the DRUID-research programme.

\section{External projects}

DRUID-members are involved in projects with external support. One major project which covers several of the elements of the research programme is DISKO; a comparative analysis of the Danish Innovation System; and there are several projects involving international co-operation within EU's 4th Framework Programme. DRUID is open to host other projects as far as they fall within its research profile. Special attention is given to the communication of research results from such projects to a wide set of social actors and policy makers. 


\section{DRUID Working Papers}

96-1 Lundvall, Bengt-Åke: The Social Dimension of the Learning Economy. (ISBN 87-7873-000-7)

96-2 Foss, Nicolai J.: Firms, Incomplete Contracts and Organizational Learning. (ISBN 87-7873-001-5)

96-3 Dalum, Bent and Villumsen, Gert:Are OECD Export Specialisation Patterns 'Sticky?' Relations to the Convergence-Divergence Debate. (ISBN 87-7873002-3)

96-4 Foss, Nicolai J: Austrian and Post-Marshallian Economics: The Bridging Work of George Richardson. (ISBN 87-7873-003-1)

96-5 Andersen, Esben S., Jensen, Anne K., Madsen, Lars and Jørgensen, Martin: The Nelson and Winter Models Revisited: Prototypes for ComputerBased Reconstruction of Schumpeterian Competition. (ISBN 87-7873-005-8)

\section{Information for subscribers.}

Subscription price for 1996 is 600 DKR (about 20 papers). The rate for single issues is $40 \mathrm{DKR}$. It is possible to make a commitment to an exchange of papers from related departments or research teams. All correspondence concerning the DRUID Working Papers should be send to:

Mette Madsen

Fibigerstræde 4, DK-9220 Aalborg OE

Tel. 45981542 11-2945

Fax. 4598156013

E-mail: mm@business.auc.dk 